\title{
Correction to: Techniques for BRDF evaluation
}

\author{
Mislene da Silva Nunes ${ }^{1}\left(\mathbb{D} \cdot\right.$ Fernando Melo Nascimento $^{2}\left(\mathbb{D} \cdot\right.$ Gastão Florêncio Miranda Jr. $^{3}$. \\ Beatriz Trinchão Andrade ${ }^{1}$ (B)
}

Published online: 22 September 2021

(c) Springer-Verlag GmbH Germany, part of Springer Nature 2021

\section{Correction to:}

\section{The Visual Computer} https://doi.org/10.1007/s00371-020-02035-9

Unfortunately the following acknowledgement was missing in original version:

This study was financed in part by the Coordenação de Pesquisa da Universidade Federal de Sergipe (COPES-UFS), Brazil (Project PVB3851-2015), and by the Coordenação de Aperfeiçoamento de Pessoal de Nível Superior (CAPES), Brazil (Finance Code 001).

The original article has been corrected.

Publisher's Note Springer Nature remains neutral with regard to jurisdictional claims in published maps and institutional affiliations.

The original article can be found online at https://doi.org/10.1007/s00 371-020-02035-9.

\footnotetext{
Beatriz Trinchão Andrade

beatriz@dcomp.ufs.br

Mislene da Silva Nunes

mislenesn@dcomp.ufs.br

Fernando Melo Nascimento

nascimento.fernandom@gmail.com

Gastão Florêncio Miranda Jr.

gastao@mat.ufs.br

1 Department of Computing, Federal University of Sergipe, São

Cristóvão, Brazil

2 Lumen Games, Aracaju, Brazil

3 Department of Mathematics, Universidade Federal de Sergipe, São Cristóvão, Brazil
} 